\title{
Integrating science and engineering practices: outcomes from a collaborative professional development
}

\author{
Brenda R. Brand
}

\begin{abstract}
Background: The Next Generation Science Standards accentuate engineering design along with scientific inquiry, emphasizing the relationship between scientific investigations and engineering design in solving problems and devising new ideas and technologies. The goal is for students to realize the importance of science and engineering in innovation and in solving many of today's challenges. The Next Generation Science Standards contends that a working knowledge and practicality of engineering design prepares students for embracing the challenges of the future. To support students in developing these capabilities, teachers are tasked with the responsibility of facilitating science instruction that integrates science and engineering practices. This is a challenge since a majority of them have little to no understanding of engineering applications.

Results: An interdisciplinary team, consisting of science education and mechanical engineering faculty and doctoral students from each discipline, and science, mathematics, and career and technical curriculum supervisors, collaborated with middle school science, mathematics, and career and technical education teachers to develop a framework for integrating engineering practices into their curricula. The exploratory nature of the project, and instructional outcomes with their students, supported teachers in developing an understanding and value for science and engineering practices. As a result, they were motivated to critique and revise their practices, aiming to develop and implement instruction that they perceived as beneficial to their students.

Conclusion: With the surge in emphasis on preparing K-12 students for the STEM workforce, initiatives devoted to exposing teachers and students to STEM applications have also increased. The findings from this study could be useful for informing these initiatives, since they reveal the learning experiences of the teachers while processing instructional strategies for integrating science and engineering practices into their curriculum. The findings highlight factors that motivated these teachers to reform their instructional practices, as well as their deliberations while endeavoring to assimilate the strategies into their curricular activities.
\end{abstract}

Keywords: Inquiry, Engineering design, Science and engineering practices, STEM, Professional development

\section{Introduction}

As technology advances in our nation, so does our dependency on it. There are growing concerns that there are insufficient numbers of individuals majoring in STEM disciplines to meet the needs. Even more of a concern is the limited amount of opportunities for students to acquire

Correspondence: bbrand@vt.edu

Virginia Tech, Southgate: Public Safety Building, 330 Sterrett Drive, Blacksburg, VA 24061, USA the foundational skills necessary to be successful STEM professionals (Hyslop, 2010). Advancing STEM education requires a move beyond an extracurricular science and mathematics outreach initiative. It requires that the applications of engineering and technology are emphasized in the contexts of curriculum and instruction (Bybee, 2010). While school districts across the nation have science, mathematics, and often career and technical education courses in middle and high schools, there is a need to

\section{Springer Open}

(c) The Author(s). 2020 Open Access This article is licensed under a Creative Commons Attribution 4.0 International License, which permits use, sharing, adaptation, distribution and reproduction in any medium or format, as long as you give appropriate credit to the original author(s) and the source, provide a link to the Creative Commons licence, and indicate if changes were made. The images or other third party material in this article are included in the article's Creative Commons licence, unless indicated otherwise in a credit line to the material. If material is not included in the article's Creative Commons licence and your intended use is not permitted by statutory regulation or exceeds the permitted use, you will need to obtain permission directly from the copyright holder. To view a copy of this licence, visit http://creativecommons.org/licenses/by/4.0/. 
provide students with rigorous K-12 STEM curricula that prepares students for post-secondary education and careers (Toulmin \& Groome, 2007). According to Ghalia, Carlson, Estrada, Hug, and Ramos (2016), implementing engineering education in $\mathrm{K}-12$ classrooms will advance the educational outcomes for students. They deem the benefits of integrating engineering to be an increase in students' motivation to learn mathematics and science content, an increase in students' understanding of mathematics and science content, and an increase in students' interest in pursuing a STEM career. Accompanying the increased emphasis on integrating engineering into $\mathrm{K}-12$ classrooms is an increase in the development and enactment of initiatives aimed at exposing students to engineering applications, such as STEM high schools, and K-12 engineering outreach programs (e.g., summer camps and after school programs). While these initiatives have been effective in exposing students to engineering, they cannot bypass teachers as the most significant sources of influence for students' achievement (Ghalia et al., 2016).

Engineering exists as a major focus in STEM education. Engineering applications advance students learning, in that open-ended problems are situated in real-world contexts. Engineering design activities develop students' problem solving skills, as well as communication and teamwork skills, particularly since collaboration is an often used instructional strategy for engaging students in solving open-ended problems (Brophy, Klein, Portsmore, \& Rogers, 2008; Roehrig, Moore, Wang, \& Park, 2012). The introduction of the NGSS (NGSS Lead States, 2013) has made engineering a core part of the science curriculum, emphasizing that science curricula that "stimulate and build interest" in STEM has the potential to increase the numbers of students pursuing STEM fields. To prepare students for the technology driven workforce of the future, the National Research Council (NRC) (2009) emphasizes the need for students' science instruction to mirror the investigative practices that scientists engage in when they are developing theories and models, and the practices that engineers use when designing solutions. Through real-world contexts, students will be prepared for the global challenges that they will confront in the not so distant future (Ross, Peterman, Daugherty, \& Custer, 2018). According to Dare, Ellis, and Roehrig (2018), many states have infused engineering into their state science standards to show the seamless relationship between the disciplines. NGSS (NGSS Lead States, 2013) advocates that engineering design is integrated throughout the science curricula, with an expectation that teachers integrate engineering practices, crosscutting concepts, and disciplinary core ideas throughout their curricula (Ross et al., 2018). However, Brophy et al. (2008) express that the realization of making engineering and use of technology transparent in society through educational efforts in PK-12 settings is a challenge.

Comfort with investigative instructional strategies that integrate engineering requires teachers who are familiar with their discipline's content and engineering practices. In traditional science and mathematics classrooms, teachers use rote teaching methods that focus on introducing and assessing factual information, which counter the expectations of applying knowledge through engineering design and open-ended problem solving (Martin, Peacock, Ko, \& Rudolph, 2015). Thus, students are not exposed to engineering because teachers are not trained to integrate science and engineering practices into their curriculum. Teachers need a conceptual understanding on how to integrate engineering into their curriculum (Ziaeefard, Miller, Rastgaar, \& Mahmoudian, 2017). Few teachers have been exposed to instruction that integrates curriculum design, engineering, and technology, so it is not surprising that they lack the knowledge on how to use engineering effectively to teach (Anderson-Rowland et al., 2003; Hsu, Purzer, \& Cardella, 2011; Yasar, Baker, Robinson-Kurpius, Krause, \& Roberts, 2006). In addition to the lack of practical knowledge, studies have shown that teachers believe limited class time, lack of materials, training, space, money, and administrative support are all barriers to integrating engineering into the classroom (Anderson-Rowland et al., 2003; Cejka \& Rogers, 2005). Professional development opportunities, as well as curriculum integrating engineering applications, are not prevalent, which means that the support that teachers need for transforming their practices is quite limited (Ross, et al., 2018). According to Yasar et al. (2006), despite the perceived barriers, the K-12 in service teachers who were participants in their study seemed to agree that design, engineering, and technology are all important to a student's education (Yasar et al., 2006).

Programs such as Project Lead the Way, the Infinity Project, and Engineering by Design ${ }^{\text {Tx }}$ were all developed in order to incorporate engineering into the K-12 curriculum. Since these programs are based upon predeveloped curricula, teachers may be limited to using lessons that restrict them to the content embedded within the activities. Therefore, teachers who have interest in teaching content other than what is focused upon in the program's curriculum may be at a loss. While these programs have proven to have some value for supporting teachers in integrating engineering, their recipebased format does not support teachers in developing the understanding for revising their pre-existing curriculum. As well, there are concerns that the activities in the pre-developed curricula such as Project Lead the Way fall short in teaching the mathematics and science content that would be expected from the science and mathematics curriculum standards (Roehrig et al., 2012). 
That could be particularly problematic for teachers, considering the highly publicized pressure on teaching content in this era of accountability. To effectively integrate engineering into their instruction, teachers need to develop strategies for adapting their own curriculum. Thus, there is a need for professional development efforts to focus on strategies for supporting teachers in integrating engineering into curriculum.

There is a dearth in professional development initiatives for supporting teachers in integrating engineering into their instruction (Roehrig et al., 2012). However, Ghalia et al. (2016) note that these initiatives, which have increased in $\mathrm{K}-12$, are designed to increase science and mathematics teachers' engineering content knowledge in an effort to enhance their students' attitudes toward engineering. Dare et al. (2018) investigated the classroom practices of high school physical science teachers involved in professional development integrating physics and engineering. They discovered that teachers having little experience integrating engineering focused more on developing "soft skills" such as teamwork or communication, rather than the engineering and physics content. The researchers determined that teacher beliefs play a critical role in determining their approach to integrating engineering. From interviews, the teachers in their study were motivated to integrate engineering into their curriculum based upon student engagement and enjoyment. These priorities were the impetus for their goals related to their instruction. The researchers emphasized the significance of an awareness of teacher beliefs to effective professional development efforts and teachers' instruction. The researchers asserted that a reconciliation of teacher beliefs was crucial to their development of instructional goals (Dare, et al., 2018; Gale, Koval, Ryan, Usselman, \& Wind, 2018).

Capobianco (2011) indicates that while teachers' uncertainty can be a challenge, it can also be the springboard for productive collaboration. Capobianco (2011) conducted a collaborative action research study focusing on one of five teachers attending a 2-week intensive preengineering summer academy for 2 years consecutively. Uncertainty was the theoretical framing. In this study, uncertainty translated into the teachers' doubt and ambiguity associated with teaching engineering design, recognizing engineering design's influence on students learning, developing the knowledge of engineering design, and with integrating engineering design into the curriculum. The researcher functioned as a critical friend who processed challenges along with the teacher as they surfaced during implementation. The dialogue between the researcher and the teacher provided an opportunity for honest critiques of the learning environment and opportunities for constructive responses to the critiques. These critiques were considered good examples of effective teacher professional learning. The researcher concluded from the findings that the opportunities for this teacher to reflect on her practice with another professional allowed her to be exposed to different viewpoints as well as support, particularly during uncertainty with new challenges.

Martin et al. (2015) examined a 6-week professional development program Engineering Summer Institute for Teachers (ESIT), which was designed to prepare mathematics and science teachers to teach high school design engineering. ESIT was implemented in response to anticipated increases in high school engineering classes. It was recognized in the development of ESIT that the teachers' professional development necessitated a modified program because a full engineering course would not be feasible for them. Thus, the ESIT program focused on providing the teachers with engineering design-based instruction (DBI), aimed at influencing their adaptive expertise. The teachers were presented with a real-world open-ended engineering problem with multiple possible solutions. The researchers conducted a pre-posttest to assess the teachers' factual knowledge, ability to solve typical problems, and their ability to apply their knowledge to reason through open-ended problems. There was evidence that DBI improved teachers' engineering innovation efficiency. While this finding is considered valuable to future professional development initiatives, the researchers concluded that an area of future study would be on how the adaptive expertise developed through the ESIT program influences the teachers' instructional practices.

Whitworth and Wheeler (2017) indicate that in order for teachers to design engineering tasks that are engaging for their students, they need a framework that aids them in distinguishing what an engineering task is. AntinkMeyer and Meyer (2016) indicate that supporting teachers in distinguishing between scientific inquiry and engineering design is important to promoting informed understandings among students. To support teachers in seeing what engineering looks like in instruction, Ross et al. (2018) developed an engineering innovation tool with a goal of providing teachers with a clear vision of what engineering infused teaching looks like. The tool was backed by literature and the NGSS (NGSS Lead States, 2013), and extended beyond a description of what engineering looks like, to providing a structure for making the engineering dimension outlined in the NGSS clear. Ross et al. (2018) concluded that NGSS (NGSS Lead States, 2013) has placed great demands on teachers, curriculum developers, and professional development facilitators. Ross et al. (2018) recognized that while it is valuable to learn how to identify curriculum that is appropriately infused with engineering, there is much to learn about transforming already developed classroom lessons into "engaging and educationally appropriate design challenges with openended solutions" (p. 17). A large majority of teachers are 
unfamiliar and have had little exposure to engineering, and they would not be prepared to facilitate engineering applications into their curriculum (Ziaeefard, et al. 2017).

\section{The Project}

Effective professional development is sustained, consists of hands-on applications of the content, is clearly applicable to teachers' daily responsibilities, and involves group participation (Garet, Porter, Desimone, Birman, \& Yoon, 2001). In addition, long-term professional development should be favored over traditional one-time workshop sessions (Brand \& Moore, 2010; NRC, 1996; DarlingHammond \& McLaughlin, 1995; Howe \& Stubbs, 1997; Kimble, Yager, \& Yager, 2006; Loucks-Horsley, Stiles, Mundry, Love, \& Hewson, 2009; Lumpe, Czerniak, \& Haney, 1999). Professional development activities should use a constructivist approach where teachers are building their knowledge through their experiences (Brand \& Moore, 2010; Kimble et al., 2006). This constructivist approach can lead to sustained changes in instructional practices (Howe \& Stubbs, 1997). Summatively, effective professional development should integrate content and pedagogy in a supportive and collaborative environment with opportunities for implementation, reflection, and revision (Brand \& Moore, 2010; Capobianco, 2011).

According to Margot and Kettler (2019), teachers need to be skilled in student-directed pedagogy in order to provide authentic problem solving experiences. They advocate for the engineering design process to be the means by which students solve open-ended problems while developing their understanding of content. This research study was an investigation of the learning experiences of teachers involved in a collaborative professional development project that was designed to identify strategies for developing student-centered pedagogy integrated with engineering design. Stated below is the overarching research question and sub questions that guided this project.

What is an effective instructional model or framework for integrating science and engineering practices into the middle school curriculum?

a. What are key instructional strategies for integrating science and engineering practices into the middle school curriculum?

b. What are key components that should be included in a model or framework integrating science and engineering practices into the middle school curriculum?

Funding was obtained through a math science partnership to develop and implement a professional development project for creating a sustainable, replicable model or framework for integrating inquiry-based practices with engineering into the middle school curriculum. The project was entitled "Inquiry By Engineering Design" (IBED). The interdisciplinary leadership team consisted of two faculty members, one from science education and the other from mechanical engineering, and two graduate students, one from each department. The science education and career and technical education district supervisors worked with the interdisciplinary team to emphasize the goals for the school district related to this focus. Prior to this professional development project, the district supervisors had embarked upon a goal of fostering collaborations across science, mathematics, and career and technical education. They requested the engagement of these groups for this professional development project.

In the initial planning phase of the professional development activities, each member of the interdisciplinary leadership team focused upon their area of expertise in designing the project activities, which is reflected in the name of the project, IBED. The input from science education focused upon students constructing their knowledge of science ideas from scientific investigations integrated with math applications. The emphasis from engineering focused upon knowledge-based decisionmaking to solve open-ended problems via engineering design. It was determined from the onset that the activities developed by the team were considered foundational components for informing a model or framework that would support teachers in integrating engineering practices into their instruction. The solidifying of an instructional model or framework would require teachers' engagement if it was going to be sustainable and replicable. In other words, the goal was to introduce an initial structure for integrating science and engineering practices into the curriculum, which would be revised based upon input from teachers during the professional development sessions and from their instructional practice. Additionally, the IBED project took into account the above mentioned recommendations for professional development. It consisted of collaborative hands-on activities with opportunities for planning, implementation, reflection, and revisions.

\section{The professional development}

Sixteen middle school teachers, fifteen females, and one male, from science, mathematics, and career and technical education, participated in the IBED project which began with a 3-day workshop in the summer. The teachers ranged from 6 to 30 years in the teaching profession. In this workshop, they participated in science and mathematics activities that integrated engineering design, which were developed by the project leadership team. The crosscurricular collaborations were introduced to the teachers as a future goal for science, mathematics, and career and 
technical education teachers at the beginning of the first day of the professional development by the district supervisors. This introduction provided context for assembling the three disciplines, particularly since the more commonly expected interdisciplinary professional development programs would primarily involve mathematics and science teachers.

While it was expected, with the long-term emphasis on inquiry-based practices, that the teachers were already acquainted with inquiry-based strategies, it was decided that inquiry-based teaching practices should be reintroduced. They were considered foundational components to student-centered instruction. Capps and Crawford (2013) conducted a study documenting the state of use of inquiry-based strategies and instruction emphasizing the nature of science. They found that the teaching practices of a majority of the teachers, who were considered well-qualified and highly motivated, reflected limited use and views of inquiry-based practices, as well as the nature of science. While the researchers expected that teachers of this background would implement inquiry-based instruction, they discovered that the teachers' instruction was mostly teacher centered. Teacher-centered or traditional science classrooms position students as passive learners and does not engage them in constructing meanings for themselves (Zhang, 2016). For teachers to integrate science and engineering practices into their instruction, there is a need to focus on how content is learned within their classrooms and how it is applied in an engineering context.

Student-centered instruction is an expectation for all classrooms, especially for the disciplines represented in this professional development program. In the workshop sessions, the teachers were engaged in inquiry-based activities integrating engineering design. The goal was to foster an understanding of the content through scientific investigations. This knowledge would be applied in solving open-ended problems. For example, one of the activities was an inquiry-based luggage ramp activity organized according to the five E inquiry instructional model (Engage, Explore, Explain, Evaluate, and Elaborate). The five E model outlines the instructional processes necessary for instruction fostering learning through inquiry. In the engagement stage, students are presented with questions or an activity to pique their interests. In the exploration stage, students are provided with hands-on experiences that foster their discovery of concepts and ideas. In the explanation stage, students report and interpret the outcomes of their explorations and are introduced to the related concepts and terminology. In the elaboration stage, students are presented with a question or activity that applies or extends the knowledge developed through their explorations. Finally, in the evaluation stage, the students reflect on their learning, and teachers assess students' understanding of concepts.

In the luggage ramp activity, the teachers, after setting up the ramp, released a container modeling luggage from varying height levels of the ramp, on varying surfaces according to the instructions. Through the questions, they were engaged in developing an understanding of potential energy, kinetic energy, energy dissipation, and coefficient of friction. Following the inquiry-based activity, the teachers were engaged in an engineering design challenge, which is considered the sixth E (Brand, Kasarda \& Williams, 2017). The teachers were tasked with using the knowledge developed through this activity to design a luggage ramp system that would transport luggage safely down the airport terminal to the runway crew according to certain specified parameters. Following these activities, the teachers critiqued the instructional strategies by reflecting on how the questions and their observations and also participation in the activities, influenced their understanding and application of the content. After participating in a day and a half of these activities, the teachers were tasked with developing activities for their classrooms using the basic structure of the inquiry-based workshop activities as a guide. These lessons were facilitated in the fall and spring semesters by the teachers and were attended by the graduate students, who were available to assist if necessary. At the end of each lesson, the teachers and graduate students completed a rubric, the Science Teaching Inquiry Rubric (STIR) developed by Bodzin and Beerer (2003) to evaluate the lesson's effectiveness. The STIR was selected by the project team because it is designed for teachers to self-evaluate the overall quality of their instruction according to the expectations of a learner-centered environment. The STIR positions the instructional environment on a continuum, from learner centered to teacher centered with descriptors identifying practices at varying levels across the continuum. For example for the first category, "Learners are engaged by scientifically oriented questions," there are five descriptive statements across the continuum. The first descriptive statement, which is more student centered, under that category is "Learner is prompted to formulate own questions or hypothesis to be tested." The second descriptive statement under that category is "Teacher suggests topic areas or provides samples to help learners formulate own questions or hypothesis." The third descriptive statement under that category is "Teacher offers learners lists of questions or hypotheses from which to select." The fourth descriptive statement under that category is "Teacher provides learners with specific stated (or implied) questions or hypotheses to be investigated." The fifth descriptive statement, which is the most teacher centered under that category is "No evidence observed." 
The teachers and the graduate student gauged whether the instructional environment exemplified more studentcentered or teacher-centered strategies by engaging the teachers in a discussion of their activities using the descriptors across the continuum. This evaluation was also designed to obtain feedback on how the instructional framework from the professional development activities was supporting them in fostering a student-centered learning environment. Mid-year, the teachers participated in a 1-day reflective session. In this session, the teachers were engaged in a whole group discussion of their implementation in terms of effectiveness and challenges and were allotted time to plan an additional lesson. In the whole group discussion, the teachers were asked to describe their activities and share their perspectives on what went well and what needed to be improved. This was an informal discussion in which the teachers were allowed to share and build off one another's inputs. They were also given the opportunity in this session to critique the instructional framework according to its practicality. As the findings will reveal later, the teachers' discussions related to the framework primarily focused upon how the students were responding to the instruction and how they were adjusting their teaching expectations and practices. The following summer, the program ended with a 2-day institute, which included follow-up reflections, more inquiry-based engineering design activities, and lesson planning. The teachers were engaged in an evaluation of the overall effectiveness of the professional development activities on their instruction. As a whole group in an informal setting, they were asked to reflect on their teaching in terms of what went well and needed to improve. They were also engaged in more activities developed by the project team, and they were invited to critique the process in terms of the students and the teachers' roles and how learning occurred. They also participated in a working session identifying and evaluating the hybrid instructional approach, which was the inquiry integrated with engineering design instructional framework they used as an instructional model for planning. The teachers' reflections on the instructional framework reflected more on how they were being motivated to think about their teaching and students' learning as a result of aligning their teaching to this framework. Thus, it was concluded that the structure was effective as a guide for supporting teachers in integrating engineering into their instruction. For that reason, the project team developed an instructional template of this framework, outlining the major components with descriptors as a guide for integrating engineering practices. Thus, the IBED framework consists of content and lesson objectives, the stages of the five $\mathrm{E}$ model, which is considered the pre-activity that fosters the understanding of the content and ends with the stages of the engineering design process as the sixth $\mathrm{E}$ of the framework (Brand et al., 2017).

\section{The research}

Sixteen teachers were interviewed at the end of the first semester following implementation and at the end of the second semester during the final session. Throughout the project, all of the reflective sessions were videotaped and transcribed. The participants' open-ended responses were analyzed using constant comparative analysis consisting of ongoing, recursive, inductive analysis (Strauss \& Corbin, 1990). This systematic form of qualitative analysis added credibility to the interpretations of the data. During open coding, the data were searched for patterns. The participants' responses were coded and listed according to the patterns that emerged and then organized into categories. Three categories emerged. The first category consisted of comments that revealed the value of this instruction for their students. The second category included teachers' fears with the practical implementation. The third category focused on teachers resolving the contradictions within their practice in their efforts to adapt their instruction to align with the IBED framework. After open coding, the categories were organized into themes with the data instances from each of the transcripts supporting the themes (Ely, Ansul, Friedman, Gardner, and Steinmetz, 1991). The categories were organized into the following themes: Teachers valued IBED instruction for their students, Teachers had fears related to the practical implementation of the IBED activities, and Teachers began to assimilate IBED instructional strategies into their preexisting frameworks. To ensure trustworthiness, the researcher, during the interpretations of the participants' responses, made every effort to remain true to the participant's statements to avoid any biased or exaggerated inferences. The researcher made every effort to represent interpretations solely according to what was stated in an effort to ensure credibility and confirmability. Trustworthiness was considered a major priority in this study. It was very important to properly represent the teachers' processes during their experiences as a major contribution to the discourse on integrating engineering practices into the K12 curriculum.

\section{Results}

Involving the teachers in informing the instructional framework through practice, reflection, and revision translated into a project that could be described as a learning community, which was the original intent. Following the initial introduction of activities by the facilitators, the teachers were positioned as leaders and evaluators. They were encouraged to pilot the strategies and to tweak them to meet their needs. It was recognized that if the teachers were going to integrate engineering practices into their curriculum as emphasized by the standards, it must be perceived as doable. The 
opportunity to process the strategies and co-develop the pedagogical approach was meaningful to the teachers. The findings indicated that the teachers' continuous reflections on their practice and the framework initially presented to them, led to an understanding of the value of activities integrating inquiry and engineering design for their students. They also developed an understanding of how this instructional approach influenced their roles and ways of being as teachers and their need to confront challenges that come along with learning and adapting new instructional strategies. As stated above, three themes emerged from the analysis of the interviews. The three themes were (1) Teachers valued IBED instruction for their students, (2) Teachers had fears related to the practical implementation of the IBED activities, and (3) Teachers began to assimilate IBED instructional strategies into their preexisting frameworks. The teachers' discussions primarily focused on how the instructional recommendations of the IBED professional development activities influenced their students' participation and their teaching philosophy and practices, which expanded upon their understanding on integrating engineering practices. Even when asked to revise the initial framework, the teachers basically reflected on the experiences they encountered during implementation and the adjustments to their beliefs, practices, and expectations. The researchers concluded that the participants valued the instructional framework as a guide for their instruction. The teachers' discussions represent the nature of deliberations that can occur when teachers are engaged in processing and revising strategies for their teaching.

\section{Teachers valued IBED instruction for their students}

The process of integrating inquiry and engineering practices into the curriculum in this professional development project was designed to be second nature or instinctive, rather than a method to employ. The following statement by the teacher indicated an awareness that the instruction is guided by principles emphasizing student engagement through discovery and knowledgebased decision-making.

To me, it is not necessarily a specific activity, it is a mindset, a way of thinking, how you question kids, what you ask them to do. It could be a writing activity. It could be a prompt. Why do you think this is happening? They are a part of your regular activities, and not necessarily a one specific little unit activity. You approach the expectation you have.

From the beginning, the main goal for the IBED approach was to emphasize instructional strategies that could be applied to any instruction. This process of questioning and open-ended problem solving was designed to support teachers in fostering a studentcentered classroom environment in which students were engaged in discovering meanings for themselves and recognizing the value of their learning through real-world applications. In the comment below, the teacher, like the one above, recognized the primary aim of this approach to be engaging students thinking. While there are desired instructional outcomes, she recognized that the strategies should encourage students to discover and pose their own solutions to problems.

It promotes thinking and sometimes there is an uncertain outcome for the knowledge base. What is clear to us, is that it helps the students to understand the choices and decisions they are making, and helps them apply data to learn from others. What we still want to master are [developing the] questions, guiding and leaning toward outcomes without losing authenticity.

IBED instruction caused the teachers to think about their roles and to define desired learning outcomes for students. In the following statement, the teacher discussed her role as helping the students realize how to use their knowledge to solve problems.

My role is to teach these kids the 'why' they have to know science, engineering, math, and technology." In other words, students should not simply memorize information, they should understand how to apply it to solve other problems.

The application of knowledge, rather than memorization of facts, is considered best practice and is an expectation for science teaching expressed in the NGSS science and engineering practices (NGSS Lead States, 2013). In the following statement, the teacher expresses the value of IBED instruction for creating a more engaging and meaningful learning environment while fostering critical thinking.

It enables the children [to] learn about long-term learning and develop the ability to think a little better. It makes for a more engaged classroom for all students and more fun for them as well. Students are not only gaining essential learning skills, but also are more engaged in IBED developed lessons and activities.

Engaging students in discovering meanings for themselves and constructing their knowledge of content reposition the teachers and the students, in comparison with teacher-centered learning environments. The students take more ownership of their learning, with the teacher functioning as the facilitator. In the following 
statement, the teacher recognized how this studentcentered approach was revered by the students and how their learning was enhanced through their engagement in the learning process.

The lessons created excitement with our students ... It made us a mentor, a facilitator instead of just getting up and being the instructors. They were kind of the instructors and they were focusing on the process instead of us giving them the right and wrong answers. They were finding different answers for some of the stuff we did.

This strategy focused professional development, with time for practical application, reflection, and revision motivated the teachers to focus on what it meant to integrate engineering into their instruction, particularly related to their roles as teachers and the roles of the students. As a result of their active involvement in the professional development activities, the teachers were able to critique and develop an understanding of the pedagogical strategies as opposed to being presented with a model that they would emulate.

\section{Teachers had fears related to the practical implementation of IBED activities}

Through IBED instruction, teachers revealed and confronted their feelings related to a loss of control in the events occurring within the learning environment. They processed these challenges, acknowledging how their previous instructional practices conflicted with IBED instruction and expressed an interest in resolving these issues. Cejka and Rogers (2005) found that teachers are reluctant to say "I don't know" to their students when posed with a question. This could be a challenge when facilitating activities that engage students in asking and answering questions and designing solutions to openended problems. One of the teachers expressed a concern about being able to answer the questions that students might ask in this student-centered environment.

I think I worry too much about trying to figure out all of the possible directions kids are going to go in. Am I prepared to help them with that? I want to be ready with whatever they ask me.

Since IBED activities involve students solving openended problems through design-based processes, there was a concern that the students may fall short in learning the intended content. This fear is exemplified in the following statement.

What if we get to the end of that activity, if they don't get that concept and we have to reteach that concept. Where is the time coming from? It's not like we'll get it next time.

Inquiry-based open-ended problem solving activities places an onus of responsibility for learning on the students. The students discover meanings through their investigations. Teachers expressed concerns related to the possible challenges with facilitating IBED-developed activities and lessons with students who are unaccustomed to figuring things out things for themselves as expressed in the following statement.

The middle school kids too, they want to know what you want them to figure out, [asking] is this right, is this right, and that also drives me ... So, if you don't have a good plan, they can turn on you. That also convinces me that I've got to make sure I've got these kids doing something besides swinging from the lights. I am still figuring it all out.

Through IBED instruction, teachers are expected to provide learning experiences that engage students in answering questions and making sense of their observations, which positions the teacher as a facilitator of students' learning. This role could be uncomfortable for teachers who are more accustomed to exercising more control as expressed in the statement below.

I agree I was thinking this morning, I am very concrete in my planning and organization of my room, and it is hard to let it go.

This teacher's observations of her students' behavior during the classroom activities gave validity to IBED instructional practices. Even with her concern that she is very structured and that some students may learn differently, this instructional approach was perceived to be worthwhile as evidenced in the comment below.

To go along with that. I am very structured, and I had a very structured teacher, and it is very hard to let that go, but I saw it in the classroom. I saw it with kids. They were learning, and more interested in learning. But again the fear is, [whether] everyone is going to get it that way. But it was worth it to take the time.

The teachers noted shifts that they would have to make in order to plan and facilitate IBED activities. They recognized that their teaching, as well as students' participation and learning, would shift. The students would assume more responsibility for their learning. Processing and reflecting on their instruction allowed them to focus on the substance, as opposed to merely focusing on the 
mechanics. While these shifts required some of them to step out of their comfort zones, they found value in the instructional approach, particularly with the student outcomes. It is important to note that the value related to student outcomes was not just focused upon the students' enjoyment and interest during the activities but also in the students' struggles to adjust to a different set of expectations for their learning.

\section{Teachers began to assimilate IBED instructional strategies} into their preexisting frameworks

As the teachers became more experienced with IBED instruction, they began to process how it would fit within their instructional practices. The teachers recognized the value of IBED instruction to their classrooms and started processing the changes that they would have to commit to in order to effectively facilitate IBED instruction. In the teacher's statement below, in addition to interpreting the major emphasis of the instructional applications, she rationalized how it would be implemented in her classroom.

I think what is clear to me is I think the STEM approach is a way of thinking about how you approach certain activities and certain lessons ... I think there are ways of doing it where you can scale it down, or you can scale it up. So I think it is a way of thinking about what you are doing in a different way.

Positive responses from students during instruction substantiated the benefit of IBED instruction to their learning. These outcomes were also influential in motivating teachers to think about how to adjust their instructional practices to utilize the IBED instructional approach. In the statement below, the teacher shares how she was going to assimilate the open-ended problem in her instructional planning.

They were so excited, so engaged, and so interested. So I am thinking I would like to do it as an ending portion of several units. When we do an energy portion that would be a very good way to end that unit. I do try to think of some ways to incorporate a project similar to this [in my instruction] with that kind of open-ended question how you came up with.

Integrating engineering introduced an open-ended approach that required adjustments in how teachers managed their instruction. This teacher acknowledged her value for the open-ended problem solving element of the instruction. She discussed how open-ended problem solving would alter her expectations, as well as provide freedom to the students to formulate their explanations and pose solutions to problems.
The whole engineering piece, how to ask questions, I noticed you on yesterday during the presentation, asking what kind of knowledge would they base their decisions on. I jotted that down. In planning, you want that to be part of it. I have got to let go. There is not a definite means to an end. I think that is what I have to shift myself around and get to, not a definite answer, but go in the direction that is okay to go with them.

The IBED approach expanded upon the teachers' conceptions of STEM and what it means in application. In the comment below, the teacher indicated that she discovered that STEM was more than a hands-on activity with equipment, but it is problem solving in which the students are using their knowledge to inform their solutions.

I tend to walk slowly through life, so it takes me a while to adapt my teaching to bring things in. I really have to see in my head before I can just throw it into my classroom. So this is helping me to see things a little better. Everything I knew about STEM was about doing something and equipment. Seeing more [about] processing things reminds me to visualize other things to put into my classroom.

IBED instruction also requires that the students shift from being passive learners to being actively engaged in investigating and discovery. They may be a little uncomfortable with having to think critically to learn the content and solve open-ended problems. The teacher, in her statement below, realized that she would have to support her students in working through their discomfort, while at the same time, growing in her value for the process

It is a process. You have to show them they need to appreciate the process. They don't get it right the first time, and when they don't, they want to throw up their hands and want you to tell them how to make it work. As a teacher, it teaches us, the teacher, to slow down and appreciate the process too.

Facilitating IBED instruction was recognized as a process that improved with experience. Understanding the framework allowed for the teachers to adjust their instructional philosophies and goals. In the statement below, the teacher captured the dynamics of implementing an instructional approach in which the value has been internalized and owned.

We imagine it [IBED] as a spiral, or depending on the day, a tornado that starts at the bottom with the 
teacher. As you try something and go back around and revisit it, you change it and go back around. And you try it again, you continually revisit and pull in more people and more ideas ... Our student is a rocket and the gases are prior knowledge in science and math. And all of it comes together to propel the student up into higher heights of inventive thinking and a new world and new ways of thinking and inventing. The project is engaging.

While the teachers' views on implementing IBED instruction varied in terms of their instructional applications, their commitment to IBED as an approach for their instruction was firm. Having a working knowledge of the instructional approach allowed them to make it their own, as indicated in the above discussions about scaling it down and where to place the open-ended project in the unit. They recognized that it was not a step by step process to follow. They considered it to be an instructional process that engages students in discovering meanings for themselves, and using that knowledge to solve open-ended problems, signifying their understanding of the content.

Not surprisingly, the teachers also discussed constraints that they considered to pose challenges to their implementation of IBED instruction. However, they did not spend a lot of time and focus on this topic, which is why constraints did not emerge as a theme in this study. The constraints were discussed in terms of the demands of standardized testing. One of the teachers described the test as "the thing we worship." While they mentioned these challenges, their discussions seemed to focus more on how they would manage them. They acknowledged that the challenges existed, but they did not speak about them as inhibiting factors. For example, in the statement below, the teacher, in discussing the pressures of standardized testing, also seemed to be contemplating strategies for managing them.

A lot comes from that overarching idea, that you have this test and they have to give answers, and everything depends on this test, and to let it go.... There are different ways to do this.

The reflective discussions with peers allowed the teachers to constructively critique and process their instructional expectations and needs in a supportive environment with like-minded individuals with similar demands and challenges. Developing a working knowledge of the instructional expectations from being engaged in them as students, applying them in practice, and tweaking them for practicality, allowed them to own the framework and assume the responsibility that comes along with that ownership.

\section{Discussion}

Stated earlier, the overarching research question was "What is an effective instructional model or framework for integrating science and engineering practices into the curriculum?" The two sub questions were (1) What are key instructional strategies for integrating science and engineering practices into the curriculum and (2) What are key components that should be included in a model or framework for integrating science and engineering practices into the curriculum? The results of this professional development project seem to reflect a progression in the teachers' orientation toward facilitating science and engineering practices in their classrooms, beginning with understanding and recognizing the value of the instructional strategies. It was determined from the teachers' discussion that the instructional framework that was presented to them in the professional development activities, and used in their instructional planning, was an effective approach for planning inquiry-based engineering design activities. This conclusion was derived from the teachers' discussions of the effectiveness of the learning environment for their students and their commitment to adjust their instructional practices so that they could provide these experiences for their students. It was also determined from the teachers' discussions that this instructional approach caused them to realize the need to shift their teaching philosophies related to their preferred learning environments and their instructional practices.

The IBED approach integrated how students learned the content with open-ended problems that required them to apply what they learned. Solutions to the openended problems were informed by a knowledge of content developed through the activities. This principle of knowledge-based decision-making, as opposed to trial and error design challenges, guided the instruction facilitated in the professional development activities, as well as the teacher's instruction in their classrooms. The trial and error design challenge format, that is a characteristic of many STEM programs, was avoided for two reasons. The first concern is that it could contribute to a false conception of what engineering is. The second concern is based upon the reality that teachers, who are being held accountable for their students' understanding of their discipline's content knowledge, would be hesitant to trust ideas that comes across as mere play for their students. This iterative process of practice, reflections, and revisions supported teachers' understanding of inquiry-based instruction and engineering applications, which validated this pedagogical approach as an effective guide for integrating engineering into the curriculum.

What is significant about the findings of this study is the window that it provides into the learning process for the teachers. The teachers were given space to realize 
these instructional strategies through their engagement and practice. The value that they placed on inquirybased instruction and engineering was as a result of their learning experiences in the professional development activities, as well as the students' outcomes during implementation. From this understanding, they were able to critique their practice and determine how they needed to adjust their philosophy and practice and most importantly, their expectations for their students. Margot and Kettler (2019), in their systematic literature review which focused on teachers' perceptions on integrating STEM, found that while teachers indicated a value for STEM education, they discussed barriers to implementation such as curricular, pedagogical and structural challenges, concerns about their students and assessments, and lack of support. According to Porter, West, Kajfez, Malone, and Irving (2019), the elementary teachers in their study who were participating in a professional development program that introduced them to curriculum integrating engineering, discussed similar limiting factors to transforming their teaching practices. The teachers in their study believed that time for them to work together and talk about their experiences with their peers would support them in sustaining their instructional practices beyond the professional development training.

The teachers in this study mentioned the pressures of the era of accountability in their reflections. However, the findings indicated that the teachers' commitment to facilitating IBED instruction was driven by their perceived value of the learning experiences for their students. From the literature survey, Margot and Kettler (2019) summarized the supports that teachers believed would enhance their abilities to integrate STEM. They were collaboration with peers, quality curriculum, district support, prior experiences, and effective professional development. The fact that these supports were taken into account in some form within the design of the IBED professional development project could perhaps explain why the teachers were able to constructively process the expectations of the NGSS (NGSS Lead States, 2013). These findings gave credence to the significance of the support structures which, in this study, provided the opportunity for the teachers to acknowledge the changes needed in their instructional practices and learning environments. The teachers in this study progressed toward integrating science and engineering practices once they understood it and took ownership of it, much like the learning experiences that they are expected to facilitate for their students. Once they realized the instructional value and understood what was needed to implement the strategies, they were able to critique their current practices in relationship to their desired outcomes.
From the beginning, the tone for this professional development was for it to be a learning community, aimed at devising strategies for integrating inquiry-based practices with engineering applications. Building upon the expertise of the leadership team, the resulting IBED instructional framework, was recognized as an approach outlining the fundamentals of the relationships between science and engineering practices. Therefore, a lesson planning template was developed for practical use in planning (Brand et al., 2017). The goal of the IBED framework is to highlight the significance of an in depth understanding of content knowledge that is necessary for solving open-ended problems and developing innovations. The IBED framework merges the five $E$ inquiry process with the engineering design process, which exists as the sixth $\mathrm{E}$ of the five $\mathrm{E}$ inquiry-based framework (Brand et al., 2017). The instructional process consists of two phases. The first phase is the pre-activity, the phase in which the students are engaged in inquiry-based activities to develop their understanding of the content. The second phase is the open-ended problem which is solved using the engineering design process. By adapting the IBED framework, the teachers felt confident that their instructional goals would be met for their students, as well as the school district's curricular expectations. The IBED framework was realized as a logical representation of best practices.

It was recognized from the findings that the teachers exited this project at varying levels of readiness regarding implementation. The most significant outcome for this professional development was the foundation that was established for all of the teachers to grow in their practice, as represented in their professional critiques about the instructional value of the strategies. This foundation is considered to be the bedrock for their instructional practices, translating into skills that they will be able to apply when planning their instruction. In other words, engaging them in critiquing the instructional framework during practice allowed them to resolve within themselves the practicality of the strategies, which is crucial to sustained application.

\section{Conclusions and implications}

As with other professional development programs cited in this study, this professional development program used pre-developed curriculum developed by project leaders to introduce teachers to instruction integrating engineering (Dare et al., 2018; Martin et al., 2015; Porter et al., 2019). However, the IBED professional development program went a step further in engaging the teachers in processing the instructional approach and piloting it to critique it for its effectiveness. The research findings from this study provided useful information related to teachers' needs when integrating science and 
engineering practices in their instruction. Regarding the limitations of this study, it is recognized that the IBED project involved a small group of teachers in a specific school district. Thus, it could not be presumed that the findings are generalizable to other populations of teachers. In addition, the snapshots of practice observed by the project staff only occurred during the professional development program. The ability to substantiate the long-term commitment and implementation of the IBED framework is not possible without reconvening the teachers to assess the current status of their instruction related to the IBED framework. An area of future study would be to survey the teachers to investigate their adherence to the IBED framework in their instruction and to examine whether it still meets their needs. That would be useful for determining the long-term viability of the framework. Additionally, to further examine the practicality of the IBED framework, it would be useful to engage a different group of teachers in similar professional development experiences. The outcomes from this additional investigation will not only be useful in assessing the effectiveness of the IBED framework, but also to evaluate the effectiveness of this collaborative professional development approach as a model for supporting teachers' understanding of integrating engineering into their curriculum.

\section{Abbreviations \\ NGSS: Next Generation Science Standards; IBED: Inquiry By Engineering Design}

\section{Acknowledgements}

Not applicable

\section{Author's contributions}

The author listed in the manuscript coded and analyzed the data and drafted the manuscript. The primary author takes full responsibility for the authorship of this manuscript. The author read and approved the final manuscript.

\section{Funding}

The Math Science Partnership funding supported the professional development.

\section{Availability of data and materials}

The datasets supporting the conclusions of this article are included in the text of the article and located on a hard drive.

\section{Competing interests}

The author declares that there are no competing interests.

Received: 10 November 2019 Accepted: 26 February 2020

Published online: 13 March 2020

\section{References}

Anderson-Rowland, M. R., Baker, D.R.., Banks, D.L., Crouch, P.E., Evans, D.L., Garcia, A., \&Yasar, S. (2003). Design, engineering, and technological expansion for K12 teachers. In 2003 ASEE Annual Conference and Exposition: Staying in Tune with Engineering Education. pp. 7211-7227.

Antink-Meyer, A. ( 1 ), \& Meyer, D. Z. (2016). Science teachers' misconceptions in science and engineering distinctions: reflections on modern research examples. Journal of Science Teacher Education, 27(6), 625-647. https://doi. org/10.1007/s10972-016-9478-z
Bodzin, A. M., \& Beerer, K. M. (2003). Promoting inquiry-based science instruction: the validation of the Science Teacher Inquiry Rubric (STIR). Journal of Elementary Science Education, 15(2), 39-49. https://doi.org/10.1007/ BF03273842.

Brand, B., Kasarda, M., \& Williams, C. (2017). Inquiry By Engineering Design: applying the sixth E. Technology and Engineering Teacher., 77(2), 22-26.

Brand, B., \& Moore, S. (2010). Enhancing teachers' application of inquiry-based strategies using a constructivist sociocultural professional development model. International Journal of Science Education, 33(7),887-913.

Brophy, S., Klein, S., Portsmore, M., \& Rogers, C. (2008). Advancing engineering education in P-12 classrooms. Journal of Engineering Education, 97(3), 369387.

Bybee, R. (2010). Advancing STEM education: a 2020 vision. Technology and Engineering Teacher., 70(1), 30-35.

Capobianco, B. M. (2011). Exploring a science teacher's uncertainty with integrating engineering design: an action research study. Journal of Science Teacher Education, 22(7), 645 Retrieved from http://search.ebscohost.com. ezproxy.lib.vt.edu/login.aspx?direct=true\&db=edsjsr\&AN=edsj. 43156624 \&site $=$ eds-live\&scope $=$ site.

Capps, D. K., \& Crawford, B. A. (2013). Inquiry-based instruction and teaching about nature of science: are they Happening? Journal of Science Teacher Education, 24(3), 497-526. https://doi.org/10.1007/s10972-012-9314-z.

Cejka, E., \& Rogers, C. (2005). Inservice teachers and the engineering design process. Proceedings of the 2005 American Society for Engineering Education Annual Conference \& Exposition. https://ceeo.tufts.edu/ documents/ conferences/2005eccr.pdf

Dare, E. A., Ellis, J. A., \& Roehrig, G. H. (2018). Understanding science teachers' implementations of integrated STEM curricular units through a phenomenological multiple case study. International Journal of STEM Education, 5(4). https://doi.org/10.1186/s40594-018-0101-z.

Darling-Hammond, L., \& McLaughlin, M. W. (1995). Policies that support professional development in an era of reform. Phi Delta Kappan, 76(8), 597-604.

Ely, M., Ansul, M., Friedman, T., Garner, D., \& Steinmetz, A. (1991). Doing qualitative research: circles within circles. New York Falmer Press.

Gale, J., Koval, J., Ryan, M., Usselman, M., \& Wind, S. (2018). Implementing NGSS engineering disciplinary core ideas in middle school science classrooms: results from the field. Journal of Pre-College Engineering Education Research, 9(1), 11-29 Retrieved from http://search.ebscohost.com/login.aspx?direct= true\&db=eric\&AN=EJ1219700\&site $=e d s-$ live\&scope $=$ site.

Garet, M. S., Porter, A. C., Desimone, L., Birman, B. F., \& Yoon, K. S. (2001). What makes professional development effective? Results from a national sample of teachers. American Educational Research Journal, 38(4), 915-945 https://doi. org/10.3102\%2F000028312038004915.

Ghalia, M. B., Carlson, R., Estrada, V., Hug, H., \& Ramos, J. (2016). Engaging K-12 teachers in engineering through a professional development program: implementation strategies, results and lessons learned. IEEE Frontiers in Education Conference (FIE), 2016, 1-7 https://doi-org.ezproxy.lib.vt.edu/10.11 09/FIE.2016.7757530.

Howe, A. C., \& Stubbs, H. S. (1997). Empowering science teachers: a model for professional development. Journal of Science Teacher Education, 8(3), 167182. https://doi.org/10.1023/A:1009487417488.

Hsu, M. C., Purzer, S., \& Cardella, M. E. (2011). Elemenatry teachers' views about teaching design, engineering, and technology. Journal of Pre-College Engineering Education Research, 1(2). 5. https://doi.org/10.5703/1288284314639

Hyslop, A. (2010). CTE's role in science, technology, engineering and mathematics. Techniques: Connecting Education and Careers., 85(3), 16-20.

Kimble, L. L., Yager, R. E., \& Yager, S. O. (2006). Success of a professionaldevelopment model in assisting teachers to change their teaching to match the more emphasis conditions urged in the National Science Education Standards. Journal of Science Teacher Education, 17(3), 309-322. https://doi. org/10.1007/s10972-006-9022-7.

Lead States, N. G. S. S. (2013). Next Generation Science Standards: for states, by states. National Academies Press.

Loucks-Horsley, S., Stiles, K. E., Mundry, S., Love, N., \& Hewson, P. W. (2009). Designing professional development for teachers of science and mathematics. Corwin Press.

Lumpe, A. T., Czerniak, C. M., \& Haney, J. J. (1999). Supporting the implementation of inquiry-based elementary science programs: setting the stage for local reform. Electronic Journal of Science Education, 3(4).

Margot, K. C., \& Kettler, T. (2019). Teachers' perception of STEM integration and education: a systematic literature review. International Journal of STEM Education, 6(1), 2. https://doi.org/10.1186/s40594-018-0151-2. 
Martin, T., Peacock, S. B., Ko, P., \& Rudolph, J. J. (2015). Changes in teachers' adaptive expertise in an engineering professional development course. Journal of Pre-College Engineering Education Research, 5(2), 35-48.

National Research Council. (1996). National science education standards. Washington, DC: The National Academies Press.

National Research Council. (2009). Engineering in K-12 education: understanding the status and improving the prospects. Washington, DC: The National Academies Press.

Porter, T., West, M. E., Kajfez, R. L., Malone, K. L., \& Irving, K. E. (2019). The effect of teacher professional development on implementing engineering in elementary schools. Journal of Pre-College Engineering Education Research, 19(2), 64-71 Retrieved from http://search.ebscohost.com/login.aspx?direct= true\&db=eric\&AN=EJ1231718\&site=eds-live\&scope $=$ site.

Roehrig, G. H., Moore, T. J., Wang, H.-H., \& Park, M. S. (2012). Is adding the E enough? Investigating the impact of $\mathrm{K}-12$ standards on the implementation of STEM integration. School Science and Mathematics, 112(1), 31-44.

Ross, J. M., Peterman, K., Daugherty, J. L., \& Custer, R. L. (2018). An engineering innovation tool: providing science educators a picture of engineering in their classroom. Journal of STEM Education: Innovations \& Research, 19(2), 13-18 Retrieved from http://search.ebscohost.com/login.aspx?direct=true\&db= a9h\&AN=130446792\&site $=$ eds-live $\&$ scope $=$ site.

Strauss, A., \& Corbin, J. (1990). Basics of qualitative research. Sage publications.

Toulmin, C. N., \& Groome, M. (2007) Building a science, technology, engineering, and math agenda. Washington, DC: National Governors Association. Retrieved from https://files.eric.ed.gov/fulltext/ ED496324.pdf

Whitworth, B. A., \& Wheeler, L. B. (2017). Is it engineering or not? To bring engineering tasks into the classroom, know what qualifies-and what doesn't. Science Teacher, 84(5), 25-29 http://search.ebscohost.com.ezproxy.lib.vt.edu/ login.aspx?direct=true\&db=ehh\&AN=123604953\&scope=site.

Yasar, S., Baker, D., Robinson-Kurpius, S., Krause, S., \& Roberts, C. (2006). Development of a survey to assess K-12 teachers' perceptions of engineers and familiarity with teaching design, engineering, and technology. Journal of Engineering Education, 95(3), 205-216. https://doi.org/10.1002/j.2168-9830. 2006.tb00893.x.

Zhang, L. (2016). Is inquiry-based science teaching worth the effort? Science \& Education, 25(7-8), 897-915. https://doi.org/10.1007/s11191-016-9856-0.

Ziaeefard, S., Miller, M. H., Rastgaar, M., \& Mahmoudian, N. (2017). Co-robotics hands-on activities: a gateway to engineering design and STEM learning. Robotics and Autonomous Systems, 97, 40-50. https://doi.org/10.1016/j.robot. 2017.07.013.

\section{Publisher's Note}

Springer Nature remains neutral with regard to jurisdictional claims in published maps and institutional affiliations.

\section{Submit your manuscript to a SpringerOpen ${ }^{\circ}$ journal and benefit from:}

- Convenient online submission

- Rigorous peer review

- Open access: articles freely available online

- High visibility within the field

- Retaining the copyright to your article

Submit your next manuscript at $\boldsymbol{\nabla}$ springeropen.com 